\title{
Efficacy of elastic-plastic constitutive models in predicting the geo-mechanical response of gas hydrate sediments
}

\author{
Sahil Wani ${ }^{*, 1}$, Rahul Samala ${ }^{1}$, Abhijit Chaudhuri ${ }^{1}$, and Ramesh Kannan Kandasami ${ }^{1}$ \\ ${ }^{1}$ Center on Subsurface Mechanics and Geo-Energy, Indian Institute of Technology Madras, Chennai, INDIA
}

\section{Introduction}

Natural gas hydrates are crystalline solids formed by the intrusion of gas molecules (such as $\mathrm{CH} 4$ generated due to biological or geological processes) into water at high pressure and low temperature. Methane gas hydrate sediments generally occur naturally in permafrost regions and in deep-sea continental shelves where the water depth is more than $500 \mathrm{~m}$ below the mean sea level. These deepwater sediments have a high concentration of methane hydrates, which are considered as a potential source of energy. Extracting these unconventional energy sources will help meet the ever-growing energy demand of a country (Jones et al., 2007). However, there are many uncertainties associated with the behavior of porous formations, especially during and after gas hydrate extraction resulting in a reluctance towards tapping these unconventional energy reserves. A critical understanding of the geo-mechanical behavior of gas hydrate sediments is essential for the long-term extraction of this unconventional energy.

\section{Phenomenological Constitutive Models}

The behavior of gas hydrate sediments is predominantly plastic due to the increase in porosity after gas extraction. Additionally, the typical gas hydrate response showed an enhanced dilation due to the presence of cementation between grains. This paper focuses on understanding the behavior of a few elastic-plastic constitutive models and establishing their efficacy in predicting the overall material response. In this study, three elastic-plastic constitutive models, such as the Methane Hydrate MohrCoulomb - MH MC (Karl et al., 2010) and the critical state models (Methane Hydrate Critical State - MH CS and Hierarchical Single-Surface Methane Hydrate model - HISS-MH models), are used to understand the geomechanical behavior of methane hydrate sediments, as shown in figure 1. Further, the influence of pore-filling and cementing hydrates on the overall mechanical response is compared. From the numerical study, it was observed that the Methane Hydrate Mohr-Coulomb model exhibits a bilinear stress-strain response (elastic-perfectly plastic) which does not capture the typical non-linear material behavior. However, the MH CS (Uchida et al., 2012 and 2016) and HISS-MH (Gai et al., 2017) models predict the overall mechanical response of gas hydrates sediments fairly accurately when compared with the experimental results (Masui et al., 2006). These models also considered the effect of the pore morphology of hydrate sediments on geo-mechanical behavior. It was observed that the cementing hydrate sediments exhibit a greater peak strength and softening response compared to pore filling hydrate sediments, as shown in figure 2 . This is due to the fact that in cementing hydrate sediments, the soil particles are strongly bonded with neighboring particles. In order to describe the enhancement of strength due to the hydrate saturation, the yield and potential function are defined such that it is dependent on the hydrate saturation. The critical state models (MH CS and HISS-MH models) captured the smooth transition from the elastic state to a plastic state and showed the softening behavior at a higher hydrate saturation level. Due to the incorporation of material degradation factors $(m)$ in critical state models, the post-peak softening response is well captured compared to MH MC model.

\footnotetext{
* Corresponding author: ce20d750@smail.iitm.ac.in
} 


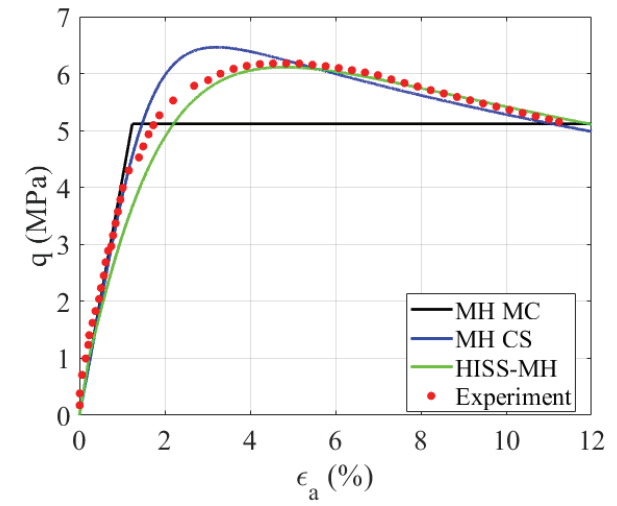

(a)

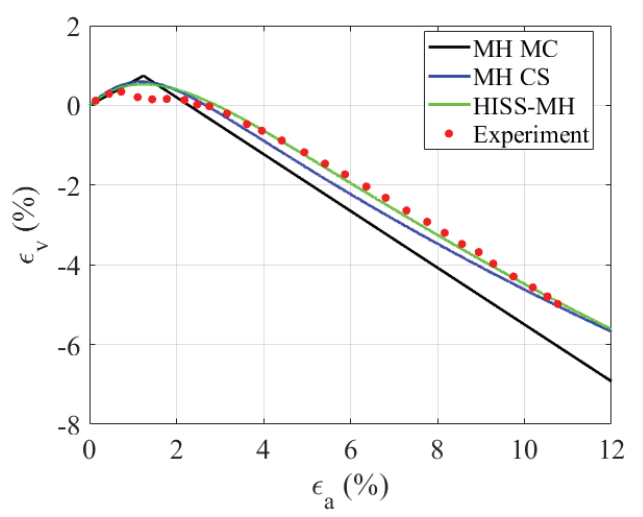

(b)

Fig. 1: Drained tri-axial tests on Nankai hydrate-bearing soil specimens $\left(\mathrm{S}_{\mathrm{h}}=37.6 \%\right.$ and confining pressure $\left.1 \mathrm{MPa}\right)$ compared with models, (a) Stress-strain response (b) Volumetric strain response

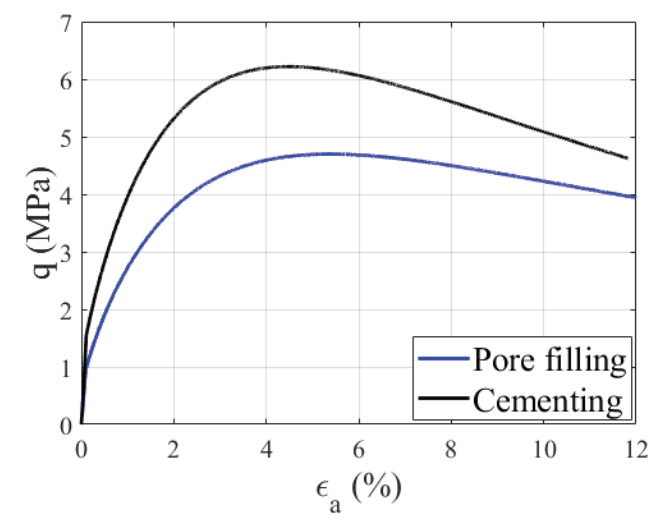

Fig. 2: Effect of pore filling and cementing hydrate sediments on the stress-strain response

\section{References}

1. Gai, Xuerui, and Marcelo Sánchez. "A geomechanical model for gas hydrate-bearing sediments." Environmental Geotechnics 4.2 (2017): 143-156.

2. Jones, Keith W., et al. "Characterization of methane hydrate host sediments using synchrotron-computed microtomography (CMT)." Journal of Petroleum Science and Engineering 56.1-3 (2007): 136-145.

3. Klar, A., K. Soga, and M. Y. A. Ng. "Coupled deformation-flow analysis for methane hydrate extraction." Geotechnique 60.10 (2010): 765-776.

4. Masui, A., et al. "Triaxial Compression test on submarine sediment containing methane hydrate in deep sea off the coast off Japan." Proceedings of the 41st Annual Conference, Japanese Geotechnical Society. 2006.

5. Uchida, Shun, Kenichi Soga, and Koji Yamamoto. "Critical state soil constitutive model for methane hydrate soil." Journal of geophysical research: solid earth 117.B3 (2012).

6. Uchida, Shun, Xiao-Guang Xie, and Yat Fai Leung. "Role of critical state framework in understanding geomechanical behavior of methane hydrate-bearing sediments." Journal of geophysical research: solid earth 121.8 (2016): 5580-5595. 